\title{
A MULTIMODALIDADE EM TEXTOS DE POPULARIZAÇÃO CIENTÍFICA: CONTRIBUIÇÕES PARA O ENSINO DE CIÊNCIAS PARA CRIANÇAS
}

\author{
Multimodality in scientific popularization: \\ contributions for children scientific education
}

Andrea Garcez Pereira ${ }^{1}$

Eduardo Adolfo Terrazan ${ }^{2}$

\begin{abstract}
Resumo: O crescente uso de imagens nos mais variados contextos torna proeminente a investigação sobre multimodalidade e suas possíveis aplicações à educação. Nesse sentido, optamos por investigar em que medida os textos multimodais de popularização científica são adequados para promover a melhoria do ensino de ciências para crianças. Investigamos a seção 'Ecologia e Meio Ambiente' do sítio Ciência Hoje das Crianças, do Instituto Ciência Hoje. Nos textos analisados, constatamos que as imagens estão permitindo a visualização de conceitos, fenômenos, eventos, elementos e/ou seres não familiares aos alunos, cumprindo, assim, duas funções básicas: a de aproximar o leitor dos conhecimentos científicos expressos verbalmente e a de ilustrar a explicação científica dada por meio da linguagem verbal. Fica evidente, ainda, que a leitura multimodal é demandada como habilidade prévia para que o leitor possa extrair, de forma bem-sucedida, as informações contidas nestes textos.
\end{abstract}

Palavras-chave: Linguagem. Texto. Imagem. Multimodalidade. Ensino de ciências para crianças.

\begin{abstract}
Since images have been used in many contexts, it is important to investigate multimodality and its educational applications. Thus, we investigate to what extent multimodal texts about science are able to improve children's scientific education in Brasil. To accomplish our aim, we analyze 'Ciência Hoje das Crianças', an online publication by 'Instituto Ciência Hoje'. The texts from 'Ecologia e Meio Ambiente', the analyzed section, suggest that their images allow the reader to recognize/visualize unfamiliar concepts, events, elements and/or beings. Based on this result, we can say that there are two basic functions attributed to these images: they put the reader in contact with the scientific knowledge expressed, partially or abstractly in verbal language, and they portray the scientific explanation already expressed in verbal language. The multimodal reading seems to be demanded as a requirement to enable the reader to understand the whole of the information.
\end{abstract}

Keywords: Language. Text. Image. Multimodality. Children scientific education.

\footnotetext{
${ }^{1}$ Graduada em Letras. Colaboradora externa, Departamento de Metodologia de Ensino, Centro de Educação, Universidade Federal de Santa Maria (UFSM). Santa Maria, RS, Brasil. <andrea.garcezpereira@yahoo.com.br> ${ }^{2}$ Graduação em Física, doutor em Educação. Docente, Departamento de Metodologia de Ensino, Centro de Educação, UFSM. Santa Maria, RS, Brasil.<eduterra@pq.cnpq.br>
}

${ }^{1}$ Rua Isidoro Grassi, 426

Bairro Medianeira - Santa Maria, RS

97.060-310 
Pereira, A. G.; Terrazan, E. A.

\section{Introdução}

As diferentes práticas sociais, nas quais nos engajamos diariamente, são permeadas por linguagem, e, para que tais interações sejam bem-sucedidas, precisamos lançar mão de constante negociação de significados. $\mathrm{Na}$ construção do significado pretendido, dispomos de diferentes modalidades semióticas, ou seja, dispomos, não só da linguagem verbal, mas também das linguagens não verbais, tais como gestos, imagens, sons e cores. De acordo com Halliday e Hasan (1991), o uso instrumental e contextualizado das linguagens, a serviço de objetivos comunicativos, é o que configura um texto. Assim, quando lançamos mão de mais de uma modalidade semiótica para atingirmos nosso objetivo comunicativo, construímos um texto multimodal.

Assim, considerando que dispomos de várias modalidades semióticas, é natural que façamos uso de mais de uma delas ao construírmos os textos que medeiam nossas práticas sociais, em outras palavras, é natural que façamos uso de textos multimodais em nosso cotidiano.

Contemporaneamente, a constituição altamente multimodal dos textos tem chamado a atenção de pesquisadores de diversas áreas, os quais consideram necessários estudos que possibilitem fazermos uso mais consciente e adequado das linguagens; pois, estas não só constituem-se como ciência, mas também permeiam as demais áreas do conhecimento. De acordo com Fairclough (2001), a capacidade de entendermos os textos que nos rodeiam nos possibilita um engajamento social mais pleno e crítico, visto que a linguagem pode ser usada para manter, questionar ou subverter a ordem social hegemônica.

Dentre as linguagens não verbais, a linguagem visual tem sido largamente utilizada na construção/transmissão de significados, sendo a sociedade atual considerada como a 'sociedade das imagens'. Contudo, é indispensável considerar que "a linguagem visual não é uma linguagem universal, mas sim culturalmente específica" (KRESS; VAN LEEUWEN, 1996, p. 3), fato que, associado ao crescente uso de imagens nos mais variados contextos e ao poder de comunicação nelas contidos, torna proeminente a investigação da multimodalidade em textos e contextos nacionais, bem como suas possíveis contribuições para a Educação.

É certo que pesquisadores brasileiros, como Martins (2002), Carneiro (1997), Nascimento (2007) e Moreira (2002), dentre outros, já vêm se dedicando ao estudo da linguagem visual no contexto escolar, e é visível o crescente interesse por este tema no Brasil, especialmente nas áreas do Ensino de Línguas e do Ensino de Ciências. Percebe-se, por meio das pesquisas divulgadas, uma tendência para a investigação sobre imagens em livros didáticos ou sobre a multimodalidade na interação presencial em sala de aula.

Não obstante a relevância de tais estudos, acreditamos ser necessário investigarmos também a ocorrência e a função assumida pela multimodalidade em textos que possam ser usados como material de apoio no Ensino de Ciências para crianças (ECC). Ambicionamos, ainda, que este trabalho some-se a outros com o mesmo enfoque e venha contribuir para a quebra da dependência quase que exclusiva - verificada, ainda hoje, por parte dos professores - dos livros didáticos.

Nesse sentido, optamos por investigar textos de Popularização Científica (PC). Esse gênero textual foi privilegiado por entendermos que, historicamente, o desenvolvimento da Ciência foi acompanhado por sua divulgação (VARGAS, 2002). Dessa maneira, acreditamos que o uso de textos de PC no ECC pode ser um meio eficaz de favorecer a formação da cidadania, como preconizada nos Parâmetros Curriculares Nacionais (1999).

Ciência \& Educasãa, v. 17, n. 2, p. 489-503, 2011 
Faz-se relevante esclarecer que, embora saibamos e estejamos engajados nos estudos e discussões a respeito da grande variação terminológica, propostos para designar textos que se destinam a informar sobre assuntos referentes à Ciência, optamos por adotar a classificação e definição proposta por Salomon (1993), a qual nos é suficiente neste momento. Salomon (1993) considera que os textos de Difusão Científica podem destinar-se a diferentes públicos, e, por isso, apresentar diferentes níveis de complexidade lexical e de conteúdo; assim, ele propõe que a denominação 'textos de Divulgação Científica' (DC) seja aplicada àqueles cujos destinatários são especialistas de áreas afins. Enquanto que PC destina-se ao público leigo, ou seja, ao leitor que, além de não pertencer a áreas afins, não está familiarizado com textos científicos e/ou acadêmicos; portanto, estes textos tendem a apresentar consensos científicos - e, por isso, não mencionam a fonte das informações -, a usar vocabulário simplificado, evitando termos especializados, e são publicados em veículos de massa, tais como jornais, revistas semanais e sítios de notícias.

Por considerarmos que a formação científica pode, e deve, ser iniciada na infância, nosso objetivo é pesquisar em que medida os textos multimodais de PC são adequados para promover a melhoria do ECC nas escolas. Para tanto se faz necessário considerar as seguintes questões:

a) Quais os tipos de imagens utilizadas em PC voltada ao público infantil?

b) Que função pode ser atribuída às imagens presentes neste gênero textual?

c) De que modo as imagens se relacionam com o texto verbal e com o objetivo comunicativo destes textos?

d) Em que medida a linguagem visual, como utilizada nestes textos, contribui para a melhoria do ECC?

\section{Revisão da literatura}

Visto que nosso objetivo é averiguar em que medida os textos multimodais de PC são adequados para promover a melhoria do ECC, nada nos parece mais coerente que ancorar nossa investigação na perspectiva da Semiótica Social - que entende a linguagem visual como vinculada à cultura e à história e socialmente motivada - e, mais especificamente, no trabalho de Kress e Van Leeuwen (1996), o qual propõe uma base teórica e descritiva de como imagens podem ser utilizadas para transmitir/construir significados.

O trabalho desses autores, por basear-se na Gramática Sistêmico-Funcional, compreende a linguagem como um sistema de escolhas potenciais não arbitrariamente motivadas, e procura explicar as implicações comunicativas de uma seleção dentro de um destes sistemas. Em concordância com a concepção de linguagem como prática social, Kress e Van Leeuwen (1996) sugerem que, ao analisarmos imagens, consideremos três aspectos concomitantes de significação: 1) qual experiência humana está sendo representada e em qual contexto ela está inserida; 2) qual a relação interpessoal estabelecida, tanto a representada como a interativa, isto é, a relação pretendida entre o que é representado e o leitor; 3) quais as escolhas feitas pelo autor para compor seu texto de maneira a atingir seu objetivo comunicativo. É fundamental lembrar, ainda, que as três representações codificam, visualmente, experiências e relações 
Pereira, A. G.; Terrazan, E. A.

vivenciadas ou ideadas fora do sistema representacional e estão permeadas pelo ponto de vista e ideologia do autor.

Com vistas ao propósito desse trabalho, discorreremos, a seguir, apenas sobre a representação experiencial, retomando sua função e apresentando seus aspectos descritivos, os quais serviram de categorias a priori em nossa análise.

A representação experiencial representa, de maneira referencial, com maior ou menor grau de abstração, objetos, fenômenos e/ou seres e suas relações - o que é representado é denominado de participante. Para tanto, dispõe-se de diversos recursos pelos quais estes participantes podem ser representados e de diferentes maneiras pelas quais eles podem estar relacionados entre si. Dentre as possibilidades de relações, há duas formas principais: representação narrativa, na qual os participantes são representados como envolvidos em processos de interação, e a representação conceitual, na qual não há processos representados.

\section{Representação narrativa}

A imagem narrativa representa uma ação em andamento, processos de mudança e/ou arranjos espaciais transitórios; essas ações são realizadas por meio de vetores e situadas, em termos de tempo e de espaço, pelo recurso de primeiro e segundo plano.

Podemos analisar as imagens narrativas considerando os seguintes processos: transacional; não transacional; de ação; de reação; mental; verbal; de conversão e de simbolismo geométrico.

\section{Processo transacional e não transacional}

A imagem transacional é aquela na qual está representado o ator - participante que pratica a ação e do qual parte o vetor - e a meta - participante que recebe a ação e é, normalmente, indicado pelo vetor.

\section{Processo de ação e de reação}

A imagem de ação é aquela na qual o vetor é emanado do ator ou na qual o ator forma o vetor.

$\mathrm{Na}$ imagem de reação o vetor é formado apenas pela linha dos olhos do reator, participante do qual parte o olhar; e o participante para o qual o olhar é dirigido chama-se fenômeno. Devido a sua natureza, este processo costuma representar seres humanos, animais ou objetos humanizados.

\section{Processo verbal e mental}

A imagem verbal ou a mental é aquela na qual os vetores são formados por balões usados para vincular os participantes a um conteúdo expresso por linguagem verbal. Estes vetores são típicos de cartoons, mas sua frequência tem aumentado em outros contextos, tais como livros didáticos e textos eletrônicos (KRESS; VAN LEEUWEN, 1996). Assim como 
A multimodalidade em textos de popularização ...

nas imagens de reação, os participantes representam humanos, animais ou objetos humanizados, e são chamados de dizente - quando representa uma ação verbal - ou de experenciador - quando o texto verbal representa um pensamento ou emoção.

\section{Processo de conversão}

A imagem de conversão é aquela na qual os vetores indicam que o participante ora é o ator, ora é a meta, ou seja, os vetores indicam processos cíclicos. Estas imagens são mais comumente utilizadas para representar fenômenos naturais ou processos naturalizados (KRESS; VAN LEEUWEN, 1996).

\section{Processo de simbolismo geométrico}

A imagem de simbolismo geométrico é aquela na qual não há participantes, os vetores representam processos abstratos e podem indicar o infinito, a direção e o sentido do processo.

\section{Circunstância}

Os cinco processos narrativos, apresentados acima, são os que apresentam os vetores como aspecto determinante de cada um deles e referem-se aos participantes principais. Há, porém, mais um tipo de participante na representação narrativa, o participante secundário, no qual o vetor não é o fator que o liga ao participante principal, mas sim outros recursos imagéticos - este tipo de participante é chamado de circunstância (KRESS; VAN LEEUWEN, 1996). Considera-se participante secundário aquele cuja ausência não afeta a base da proposição narrativa, embora possa afetar a representação do significado completo. As circunstâncias podem ser de três tipos:

a) Circunstância de local, a qual situa e relaciona os outros participantes a um participante específico, o setting. Isto requer um contraste entre primeiro e segundo plano; este contraste pode ser realizado de quatro maneiras diferentes, as quais podem ser utilizadas separadamente ou em combinação e em diferentes graus.

b) Circunstância de acompanhamento, na qual é possível identificar participantes distintos sem que, contudo, haja vetores relacionando-os.

c) Circunstância de significado são objetos que, frequentemente, representam as ferramentas usadas nos processos de ação. Não há vetores explícitos entre as ferramentas e seus usuários, mas, em alguns casos, as próprias ferramentas podem formar vetores, que as ligam ao usuário e/ou que realizam os processos de ação. 
Pereira, A. G.; Terrazan, E. A.

\section{Representação conceitual}

A imagem conceitual representa os participantes de forma generalista, relativamente estável e atemporal, representando-os em termos de classe, estrutura e/ou significado. Assim, o participante é representado de forma a ser percebido como estático e pode ser representado de acordo com o aspecto classificatório, analítico ou simbólico.

\section{Processo classificatório}

Neste processo, os participantes são representados em termos taxonômicos, desse modo, eles se relacionam por meio de subordinação e superordenação. A taxonomia pode ser de dois tipos: implícita ou explicita.

a) Taxonomia implícita é aquela na qual não há nomeação dos participantes subordinados ou superordenados, cabendo, assim, ao leitor estabelecer as relações existentes entre eles, por meio de inferência, ou localizar tal classificação no texto verbal que possa estar acompanhando a imagem. $\mathrm{Na}$ taxonomia implícita, representada visualmente, a equivalência entre os participantes subordinados é estabelecida pela composição simétrica, ou seja, os participantes são representados com igual distância uns dos outros, com o mesmo tamanho e com a mesma orientação, vertical ou horizontal. Além da simetria, para representá-los de forma estável e atemporal, eles são, normalmente, representados de maneira descontextualizada.

Outra maneira de representação da taxonomia implícita é a diagramática, na qual há a presença do superordenado e os participantes podem ser representados tanto visual como verbalmente; mas a taxonomia é sempre representada visualmente (KRESS; VAN LEEUWEN, 1996).

b) A taxonomia explicita é diagramática, pode ou não ter a presença de imagens, e é representada em forma de "árvore", constituindo níveis hierárquicos. Assim, esse tipo de representação permite que um participante seja superordenado em relação a determinado(s) participantes(s) e subordinado a outro(s). Kress e Van Leeuwen o chamam de participante interordenado (1996).

Não se deve supor, contudo, que a representação taxonômica possa ser reduzida à simplicidade da representação hierárquica e estática de um dado sistema, pelo contrário, Kress e Van Leeuwen (1996) apontam a diversidade e complexidade das representações taxonômicas.

\section{Processo analítico}

Este processo representa os participantes em suas relações de estrutura em termos de parte-todo: o participante que representa o todo é denominado portador e as partes são denominadas atributos possessivos. As Imagens Analíticas são pouco detalhadas, somente as características principais do portador são representadas, por isso, desenhos com diferentes graus de esquematização são mais usados neste tipo de representação do que fotografias ou desenhos artísticos altamente detalhistas. A presença de rótulos verbais para identificar os 
A multimodalidade em textos de popularização ...

atributos possessivos representados imageticamente é outra característica típica das imagens analíticas (KRESS; VAN LEEUWEN, 1996).

Embora o objetivo da imagem analítica seja identificar o portador e permitir ao leitor uma averiguação minuciosa de seus atributos possessivos, ela tem um propósito mais interacional do que representacional, pois ela é endereçada diretamente ao leitor, ainda que de forma impessoal.

Há, ainda, outras formas de representação analítica, as quais possuem características específicas. A seguir, apresentaremos apenas a sistematização das três macrodivisões propostas por Kress e Van Leeuwen (1996):

a) processo analítico desestruturado - este tipo de imagem nos mostra os atributos possessivos, mas não como ficam juntos, representando o portador. Os atributos possessivos formam apenas uma espécie de lista desordenada das partes;

b) o processo analítico temporal parece ocupar um lugar intermediário entre o processo narrativo e o analítico, pois representa dimensões temporais, com eventos consecutivos e interdependentes, que formam uma linha do tempo;

c) o processo analítico exaustivo e inclusivo realiza representações espaciais, essas estruturas podem ser mapas, topologias, topografias, circuitos ou gráficos, entre outros. A representação exaustiva é aquela que representa todos os atributos possessivos do portador de maneira detalhada, que juntos formam uma estrutura complexa. Já a representação inclusiva mostra apenas alguns dos atributos possessivos do portador, deixando-o com lacunas, sem a preocupação de representá-lo de forma plena.

\section{Processo simbólico}

Representa o significado ou a identidade do participante representado, o qual é denominado portador. Quando há outros participantes, estes representam o significado ou a identidade do portador e são denominados de atributos simbólicos, que são conferidos ao portador. Os atributos simbólicos são objetos salientes, devido a seu tamanho exagerado, detalhamento, foco ou cor. Estas características fazem com que ele seja percebido como 'fora de lugar', isto é, não fazendo parte comum do cenário. Quando o atributo simbólico é representado na figura de um ser humano, este não participa de ação, mas é representado como pousando para o leitor (KRESS; VAN LEEUWEN, 1996).

Porém, quando a imagem representa somente o portador, sua descrição costuma ser verbal e situada abaixo da imagem, e esse participante é denominado de simbólico sugestivo, o qual representa o significado ou a identidade do portador como derivadas das qualidades do ser/objeto em si (KRESS; VAN LEEUWEN, 1996).

Ainda que possamos classificar as imagens por seus processos mais evidentes, é importante relembrar que cada imagem pode conter processos subjacentes ou secundários que permitiram classificá-las de outra forma, ou seja, a classificação de imagens depende tanto do ponto de vista, como do objetivo do analista. Assim, reforça-se a característica contextodependente dos significados construídos/transmitidos por meio de imagens. 
Pereira, A. G.; Terrazan, E. A.

\section{Metodologia}

Tendo em vista o escopo deste trabalho, optamos por analisar uma publicação voltada ao letramento científico infantil. Portanto, procuramos identificar publicações que já fossem utilizadas como material de apoio no ensino de ciências para crianças, ou que tivessem o potencial de serem utilizadas didaticamente; além do aspecto da potencialidade, pesquisamos por publicações que nos permitissem identificar o objetivo comunicativo da mesma, sendo este declarado com clareza pelo veículo. Em nossa busca, identificamos o Instituto Ciência Hoje (ICH), vinculado à Sociedade Brasileira para o Progresso da Ciência (SBPC), o qual é responsável por um projeto de divulgação científica através de uma série de publicações, tais como as revistas Ciência Hoje e a Ciência Hoje das Crianças e os livros da série Ciência Hoje na Escola. Além destas publicações gráficas, desde 1997, o ICH mantém um sitio de divulgação científica na internet: Ciência Hoje Online, o qual disponibiliza, dentre outros, o sítio Ciência Hoje das Crianças (CHC). Ao mesmo tempo, o sítio CHC explicita seu objetivo comunicativo declarando-se "um material de aprendizagem, facilitador da compreensão do mundo e da relação com ele, mediante o acesso aos diferentes saberes, fornece o suporte necessário a toda comunidade escolar"3.

Visto que o sítio CHC contempla os dois pré-requisitos por nós estabelecidos (ser potencialmente utilizável como material de apoio no Ensino de Ciências para crianças e ter seu objetivo comunicativo claramente declarado pelo veículo), decidimos utilizá-lo como fonte de documentos para nosso estudo. Outros fatores que contribuíram para esta escolha foi o sítio ter acesso gratuito e disponibilizar seus textos para impressão e manipulação.

Descreveremos, brevemente, o sítio, apenas para explicitar nosso procedimento. $\mathrm{O}$ sítio CHC apresenta dois links em destaque no topo da página: "quero irpara o site principal", que leva para o sítio do ICH, e o "revista CHC", que leva para a página de divulgação da revista CHC impressa. Este link, da CHC impressa, disponibiliza resumos dos artigos que compõem o último número da revista e alguns artigos completos para leitura online, bem como links para os arquivos dos números anteriores, os quais são organizados por ano de publicação desde 2000. Além dos dois links, já descritos, a página inicial traz diversos links de matérias e artigos. $\mathrm{Na}$ lateral esquerda da página, existem outros 18 links para diferentes seções do sítio, com assuntos científicos, culturais e de interesse público.

Das 18 seções mencionadas, navegamos pelas 11 voltadas às ciências. Dentre elas, selecionamos a seção "Ecologia e Meio Ambiente", uma vez que, além de concentrar um número razoável de textos de PC, o tópico Meio Ambiente é um dos temas transversais sugeridos nos Parâmetros Curriculares Nacionais do Ensino Fundamental (1999). Também elegemos esta temática por entendermos o letramento científico como possível promotor da biorresponsabilidade, a qual ocorrerá somente se o indivíduo compreender as transformações que acontecem em seu cotidiano, tais como: a degradação dos recursos naturais que afetam o equilíbrio da Terra, como decorrentes, em grande parte, dos hábitos de vida e consumo da sociedade contemporânea.

${ }^{3}$ Disponível em: <http://www.cienciahoje.uol.com.br/materia>. Acesso em: 24 fev. 2009. 
Ao proceder à análise da seção selecionada, verificamos que, dos 25 textos que a compunham, 13 eram de interesse público (notícias de cunho geral), dois eram propagandas e dez de popularização científica. Dos dez PC, um estava postado duas vezes, assim, nosso corpus ficou composto por nove PC destinados ao público infantil. É importante ressaltarmos que o tamanho do corpus é um fator limítrofe em nossa pesquisa, pois sendo ele composto por um pequeno número de textos, serão necessários estudos futuros que abranjam outras seções do veículo como forma de comprovação ou refutação do mesmo como fonte adequada de textos multimodais que possam ser utilizados no ECC. Contudo, consideramos que, com esta amostra, já será possível estabelecermos algumas conclusões e indicações que contribuam para área.

Tendo selecionado nosso corpus, o próximo passo foi estabelecer o papel das imagens ${ }^{4}$ de acordo os critérios da Representação Experencial, como proposta por Kress e Van Leeuwen (1996), e já discutida na revisão da literatura.

Após a análise das imagens, passamos a observar o texto verbal, isto é, examinamos, primeiramente, se havia legendas e se estas se sobrepunham ou acrescentavam informação à linguagem visual - o texto formado pela imagem e sua legenda é denominado texto periférico. Em seguida, consideramos o texto periférico em relação ao corpo do texto (esta denominação refere-se ao texto verbal, excluindo-se a legenda, título, subtítulo e fonte), para isso, usamos os mesmos critérios de análise das legendas, ou seja, se as imagens e suas legendas sobrepunham ou acrescentavam informação ao corpo do texto.

\section{Resultados e discussão}

Nos nove textos provenientes da seção "Ecologia e Meio Ambiente" do sítio CHC, identificamos 25 imagens classificadas nas categorias Conceitual (vinte) e Narrativa (cinco).

Quanto à distribuição das imagens por texto, cabe destacar que a maioria dos textos continha de duas a três imagens; entretanto, dois textos se destacaram por terem maior concentração imagética: em um deles ocorreram cinco imagens, e em outro texto, seis.

A ocorrência das cinco imagens narrativas concentrou-se em um único texto, cujo título é "A História do Brasil vista das margens de um rio", o qual se propõe a narrar as condições e o uso dos recursos hídricos desde o descobrimento até a urbanização de nosso país.

Veja, por exemplo, as imagens 1 e 2, correspondentes à segunda e à quinta imagens apresentadas no referido texto ambas classificadas como imagem narrativa transacional de ação.

\footnotetext{
${ }^{4}$ Estendemos, aqui, nossos agradecimentos às alunas Ana Paula de Carvalho e Halana Garcez Borowsky, acadêmicas do curso de Pedagogia da UFSM, pela cooperação no mapeamento do site CHC, seleção do corpus e na análise preliminar.

${ }^{5}$ Disponível em: <http://chc.cienciahoje.uol.com.br/noticias/ecologia-e-meio-ambiente/a-historia-do-brasilvista-das-margens-de-um-rio/?searchterm=None $>$. Acesso em: 24 fev. 2009.
} 
Pereira, A. G.; Terrazan, E. A.

Na imagem 1, é possível perceber, pelo menos, seis ações em andamento, as quais são representadas pelos vetores criados pelo corpo do participante 1 (P1), pelo peixe e pelo remo segurado pelo participante 2 (P2) e pela banana segurada pelo participante 3 (P3), bem como por seu braço e perna. Estes vetores podem ser expressos verbalmente pelos verbos de ação: mergulhar; pescar; caminhar; sorrir; navegar e comer. Em primeiro plano, temos um rio e, em segundo plano, o céu, o sol, a bananeira e a areia; este cenário pode ser expresso verbalmente pelas circunstâncias de tempo e de lugar: de dia, no rio.

Nessa imagem, os participantes 1,2 e 3 são atores e o rio é a meta. Sendo que a banana, segurada pelo P3, é a ferramenta que indica o processo que pode ser expresso pelo verbo de ação comer; assim, a banana é a circunstância de significado.

$\mathrm{Na}$ imagem 2, os vetores são criados pela inclinação do corpo, pelo olhar e pela língua do
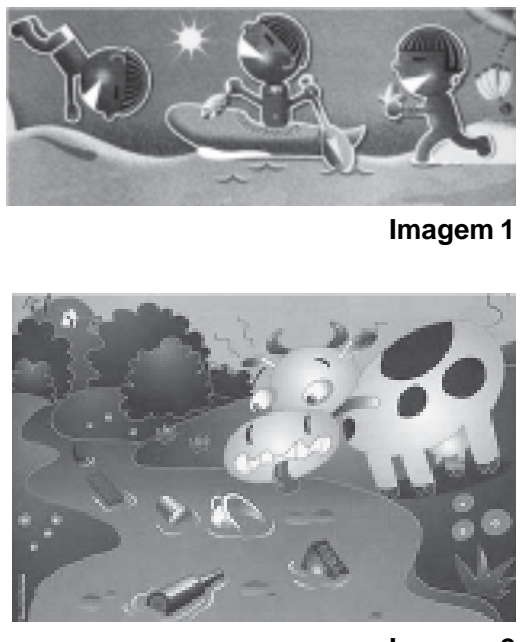

Imagem 2 participante. Estes vetores podem ser expressos verbalmente pelos verbos de ação: beber; repugnar ou enojar. Em primeiro plano, temos um rio e, em segundo plano, casas (simbolizando urbanização) e um céu alaranjado; este cenário pode ser expresso verbalmente pelas circunstâncias de tempo e de lugar: de dia, no rio. Nessa imagem a vaquinha é o ator e o rio a meta.

Em ambas as imagens do texto "A História do Brasil vista das margens de um rio", a meta e a circunstância de tempo e de lugar são as mesmas. As diferenças entre as duas imagens são criadas pela mudança em suas condições e especificidade, isto é, o rio permanece como meta e circunstância de lugar, contudo, ele é representado em seu estado natural na imagem 1 e como degradado na imagem 2; a circunstância de tempo continua sendo de dia, mas na imagem 1 o dia é representado pelo céu azul e pelo sol, transmitindo uma ideia de dia claro e agradável, enquanto, na imagem 2, o dia é representado por um céu alaranjado e turvo, transmitindo uma ideia de entardecer com matizes típicos da poluição. Os participantes foram alterados: na imagem 1, os atores são três índios, o que reforça o estado natural do rio, e, na imagem 2, uma vaquinha (humanizada pela expressão facial), que conota a presença do homem branco e a domesticação. Além da mudança dos atores, os processos são reduzidos de seis para dois, demonstrando a diminuição das utilidades e da adequação dos rios como recurso e suporte da vida.

Assim, consideramos que a presença das imagens narrativas está diretamente relacionada ao objetivo do texto, e, apesar de as imagens estarem apenas sobrepondo informações ao texto verbal, elas auxiliam a criança na compreensão da degradação deste recurso como resultante de um processo sócio-histórico.

Constatamos a ocorrência majoritária das imagens conceituais. Esse tipo de imagem, como já mencionado na revisão da literatura, é usado para representar os participantes de forma generalista, relativamente estável e atemporal; assim sendo, essas imagens possibilitam a representação dos participantes de forma identitária ou estrutural e suas relações de constituição ou de classificação. 
Confira alguns dos anfíbios ameaçados de extinção.

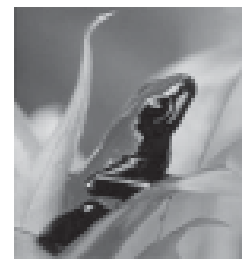

O Dendrobates galactonotus é um anfíbio abundante na Amazônia, ameaçado pelo desmatamento, pela caça e pelas inundações para a construção de hidrelétricas no Tocantins (foto: Ron Holt).

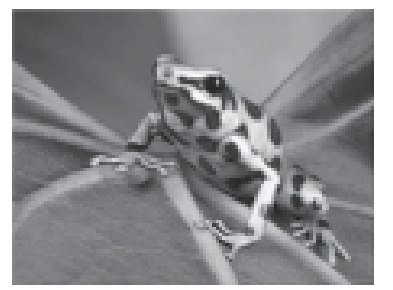

Comum nas Américas Central e do Sul, o Dendrobates auratus sofre com o desmatamento e a caça ilegal. Não bastasse isso, cientistas encontraram um deles com o fungo que ameaça várias espécies de anfíbios (foto: Ron Holt).

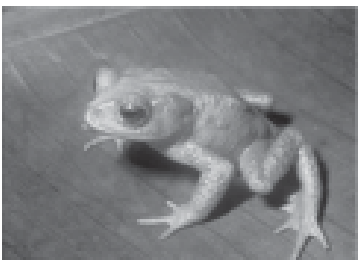

O sapo dourado (Bufo periglenes) foi visto pela última vez em 1989. Os especialistas acreditam que ele tenha sido extinto pela poluição do ar e pelo aquecimento do planeta (foto: Wikipédia).
Dentre as vinte imagens conceituais, cinco são classificatórias e representam uma taxonomia.

A imagem 3, do texto "Salvem os anfíbios", representa uma taxonomia implícita, isto é, não há hierarquia explicitada entre os participantes, cabendo ao leitor estabelecer as relações existentes entre eles. Nesse exemplo, a taxonomia é representada visualmente e a equivalência entre os participantes é estabelecida pela composição simétrica e pela forma estável, atemporal e descontextualizada com que os anfíbios estão representados. As outras 15 imagens são simbólicas e representam espécies ou lugares; o uso deste tipo de imagem pode servir para auxiliar as crianças na visualização do portador, cuja descrição verbal teria de ser exaustiva, e que, ainda assim, provavelmente, não atingiria o nível necessário de proximidade com o referente. No caso da imagem 4, do texto "Caramujo Africano: problema gigante", é representado somente o portador, cuja descrição é feita verbalmente e situada abaixo da imagem (legenda), que, nesse caso, é denominado de atributo simbólico sugestivo.

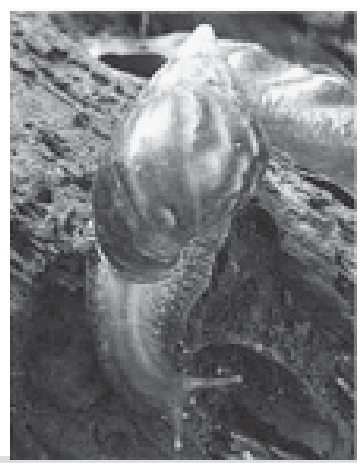

Se ligue nas listras marrons na concha do caramujo. Essa é a dica de que o molusco que você está vendo é mesmo um Achatina fulica, e não outra espécie qualquer.

Imagem 4

\footnotetext{
${ }^{6}$ Disponível em: <http://chc.cienciahoje.uol.com.br/noticias/ecologiae-meio-ambiente/salvem-os-anfibios>. Acesso em: 24 fev. 2009.

${ }^{7}$ Disponível em: <http://chc.cienciahoje.uol.com.br/noticias/ecologiae-meio-ambiente/caramujo-africano-problema-gigante/>. Acesso em: 24 fev. 2009.
} 
O atributo está descrevendo a identidade do portador, explicitando características inerentes à espécie representada; nesta imagem as listras marrons são salientadas como característica identitária do portador.

Constatamos, também, que das 25 imagens, 17 apresentavam legenda. Destas, apenas uma era narrativa, as demais legendas acompanhavam imagens conceituais.

Ao analisarmos a relação entre a legenda e a imagem verificamos que: a) somente uma imagem narrativa apresentou legenda, e essa acrescenta informações à imagem, situando-a temporal e geograficamente; b) apenas duas das 16 legendas que acompanhavam as imagens simbólicas relacionavam-se por mera sobreposição das duas linguagens, ou seja, elas foram usadas unicamente para nomear a espécie e o fenômeno representados; c) as 14 legendas restantes foram utilizadas para acrescentar algum tipo de informação à imagem. Deste modo, é plausível dizer que as linguagens visual e verbal, contidas nas imagens e em suas legendas, são, predominantemente, complementares, e que o significado do texto periférico foi construído de forma que a apreensão de seu significado depende da habilidade de leitura multimodal do leitor.

Na imagem do caramujo africano, por exemplo, a legenda orienta o leitor a observar a característica distintiva da espécie, além de informar o nome científico da espécie.

Da análise da relação texto periférico e corpo do texto, percebemos que: a) houve relação entre todos os componentes textuais analisados, ainda que em alguns casos essa relação tenha demandado grande grau de abstração do leitor para estabelecê-la; b) duas das Imagens Narrativas relacionam-se com o corpo do texto somente por sobreposição, ou seja, elas são utilizadas apenas para ilustrar a narração verbal. Outras três, além de ilustrarem a narração verbal também acrescentam informação a ela. É importante ressaltar que a única Imagem Narrativa legendada, a qual é uma fotografia do centro do Rio de Janeiro em 1904, embora se relacione com o texto verbal, por exemplificar o início das grandes cidades brasileiras, é problemática (veja imagem 5 e extrato) ${ }^{8}$. Isso porque o texto verbal não menciona esta cidade em particular, mas sim a cidade de São Paulo; assim, podemos considerar que ela pode causar interpretações divergentes: a primeira é de que há uma incongruência

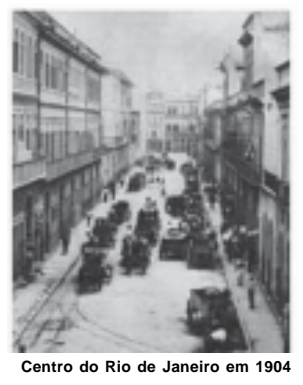

Imagem 5 entre o texto verbal e o visual, o que desmerece o texto, e, a segunda, exige alto grau de abstração por parte do leitor para que ele possa atribuir à imagem o significado de exemplo visual que acrescenta informação ao texto verbal, ou seja, podendo significar que a urbanização se deu em diferentes lugares simultaneamente e que isto está expresso por dois exemplos codificados diferentemente no texto;

c) das 15 imagens simbólicas, as quatro simbólicas atributivas são utilizadas somente para sobrepor a informação já veiculada no texto verbal, como uma forma de ilustração do mesmo.

\footnotetext{
${ }^{8}$ Disponível em: <http://chc.cienciahoje.uol.com.br/noticias/ecologia-e-meio-ambiente/a-historia-do-brasilvista-das-margens-de-um-rio/?searchterm=None>. Acesso em: 24 fev. 2009.
} 
As outras 11 acrescentam informações ao corpo do texto - nestes casos, as legendas foram usadas para descrever os atributos inerentes ao portador, ou seja, estas eram imagens simbólicas sugestivas.

$\mathrm{Na}$ imagem $6^{9}$, por exemplo, a legenda acrescenta informação direcionando o olhar do leitor para a chapada, que está em segundo plano, conceituando-a e situando-a geograficamente; já o corpo do texto menciona as chapadas sem conceituar, assim, embora o corpo do texto não faça referência à imagem, há interdependência entre o texto periférico e o corpo do texto para a apreensão de significado.

A partir dos aspectos constatados, podemos dizer que, nos textos analisados, as imagens estão permitindo a visualização de conceitos, fenômenos, eventos, elementos, objetos e/ou seres não familiares aos alunos, quer seja por sua abstração ou por sua especificidade e, assim, cumprindo duas funções básicas: a de aproximar o leitor dos conhecimentos científicos expressos verbalmente (esta função está relacionada às imagens xonceituais classificatórias e

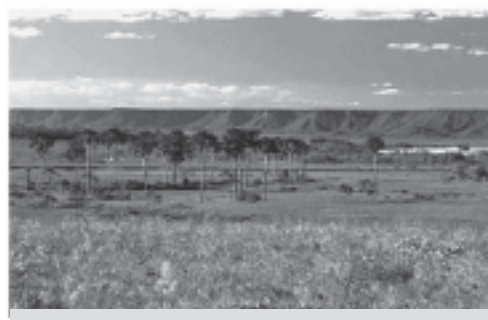

Chapadas são formações rochosas elevadas que possuem uma porção bem plana na parte superior. A da foto fica na região do Jalapão, em Tocantins. (foto: Mário Barroso/Conservação Internacional).

Imagem 6

às simbólicas sugestivas) e a de ilustrar a explicação científica dada por meio da linguagem verbal (esta função está relacionada às imagens conceituais simbólicas atributivas e às imagens narrativas). Nossos dados indicam, ainda, que as legendas foram recursos utilizados para ampliar a informação mediada pelo texto periférico.

O objetivo dos textos de PC do sítio CHC, como declarado na página inicial do sítio, é não só o de difundir conhecimentos científicos ao público infantil, mas, também, o de servir de auxilio paradidático aos professores dos anos iniciais. Contudo, apenas um dos textos analisados fez referência explícita à imagem e seu significado no texto. Assim, fica evidente que a leitura multimodal é demandada como habilidade prévia para que o leitor possa compreender, de forma efetiva, as informações contidas nestes textos.

\section{Considerações finais}

Superar a abstração dos conceitos e explicações científicas feitas tradicionalmente de maneira monomodal, é considerado um dos grandes desafios enfrentados pelos professores; por isso, o Ensino de Ciências é entendido, atualmente, como intrinsecamente visual. Nesse sentido, a literatura da área propõe recursos didáticos, como: uso de objetos, de analogias, de experimentos, de imagens e de textos, os quais visam potencializar a aprendizagem científica

${ }^{9}$ Disponível em: < http://chc.cienciahoje.uol.com.br/noticias/ecologia-e-meio-ambiente/como-um-bau-cheiode-tesouros/como-um-bau-cheio-de-tesouros-0 >. Acesso em: 24 fev. 2009. 
Pereira, A. G.; Terrazan, E. A.

infantil. Assim, apesar de termos verificado que os textos de PC provenientes da seção "Ecologia e Meio Ambiente" do sítio CHC fazem uso, ainda que limitado, da multimodalidade, para serem utilizados no ECC de modo que os alunos se beneficiem das imagens, esses textos dependem da mediação/orientação dos professores, dos quais a habilidade de leitura multimodal é demandada como conhecimento prévio. Entretanto, sabe-se que grande parte dos professores ainda não está acostumada à leitura multimodal, o que torna tais recursos de uso limitado. Logo, os recursos multimodais parecem estar acrescentando outro desafio aos professores, o do desenvolvimento do próprio letramento visual, o qual se faz indispensável para que possam apropriar-se mais adequadamente desses recursos em sua prática pedagógica.

Portanto, consideramos necessário algumas ações que se destinem à capacitação dos professores, não só de ciências, mas de todas as áreas, em leitura multimodal. Isso para que eles possam atingir seus objetivos de ensino com maior êxito. Para que se possa promover, com efetividade, a habilidade de leitura multimodal dos alunos da Educação Básica, também se faz urgente desenvolver o próprio desenvolvimento dessa habilidade por parte dos professores, tanto os em serviço como os professores em formação inicial. Portanto, sugerimos ações tais como:

- Criação de grupos voltados ao estudo e à aplicação da multimodalidade ao ensino;

- Elaboração de programas de formação continuada que promovam a leitura multimodal entre os professores em serviço;

. Oferta de disciplinas complementares de graduação sobre multimodalidade para professores em pré-serviço;

. Inclusão, nos currículos de graduação de cursos de Licenciatura, de disciplinas que contemplem a habilidade de leitura multimodal dos acadêmicos.

A fim de que nossas indicações de utilização de textos multimodais de popularização científica como recurso promotor da melhoria do EEC se efetivem é necessário, primeiramente, gerar uma expansão significativa da habilidade de leitura multimodal dos professores. Assim, demos início a um grupo de trabalho voltado ao Ensino de Ciências e à Multimodalidade. Dentre as atividades previstas pelo grupo, incluem-se: seminários de estudos internos para discussão contínua da literatura relativa à leitura multimodal; seminários e oficinas voltados aos professores em serviço; seminários de estudos destinados aos professores em formação inicial; elaboração de módulos didáticos a serem implementados em sala de aula. Com isso, pretendemos, não só legitimar a eficácia dos recursos multimodais como facilitadores do ECC, mas também dar início às ações que julgamos necessárias para o aprimoramento dos professores em leitura multimodal; ainda que, num primeiro momento, saibamos que nossas ações resultem em melhoria somente em uma esfera de ação imediata, consideramos de extrema importância dar início a essas ações e, assim, motivar outros a ações similares. 
A multimodalidade em textos de popularização ...

\section{Referências}

BRASIL. Ministério da Educação e Cultura. Parâmetros Curriculares Nacionais -

Ensino Fundamental. Brasília: MEC, 1999.

CARNEIRO, M. H. S. As imagens no livro didático. In: ENCONTRO DE PESQUISA E EDUCAÇÃO EM CIÊNCIAS, 1., 1997, Águas de Lindóia. Atas... Águas de Lindóia, 1997. p. 366-373.

FAIRCLOUGH, N. Discurso e mudança social. Brasília: Editora Universidade de Brasília, 2001.

HALLIDAY, M. A. K.; HASAN, R. Language, context and text: aspects of language in a social-semiotic perspective. Oxford: Oxford University Press, 1991.

KRESS, G.; VAN LEEUWEN, T. Reading images: the grammar of visual design. London: Routledge, 1996.

MARTINS, I. Visual imagery in school science texts. In: GRAESSER, A.; OTERO, J.; DELEON, J. A. (Eds.).The psychology of scientific text comprehension. Hillsale: Lawrence Erlbaum Associate Publishers, 2002.

MOREIRA, I. C.; MASSARANI, L. Aspectos históricos da divulgação científica no Brasil. In: MASSARANI, L.; MOREIRA, I. C.; BRITO, F. (Orgs.). Ciência e público: caminhos da divulgação científica no Brasil. Rio de Janeiro: Casa da Ciência/Centro Cultural de Ciência e Tecnologia da Universidade Federal do Rio de Janeiro, Fórum de Ciência e Cultura, 2002.

NASCIMENTO, S. S. A linguagem e a investigação em educação científica: uma breve apresentação. In: NARDI, R. (Org.). A pesquisa em ensino de ciências no Brasil: alguns recortes. São Paulo: Escrituras, 2007. p. 131-142.

SOLOMON, J. Teaching science, technology and society: developing science and technology series. Buckingham and Philadelphia: Open University Press, 1993.

VARGAS, C. F. As regularidades e as possibilidades de progressão temática nos textos de popularização científica. 2002. 125f. Dissertação (Mestrado em Estudos Linguísticos) - Universidade Federal de Santa Maria, 2002. 